\title{
Review of CFTR Modulators 2020
}

\author{
Danielle Goetz ${ }^{1}$ and Adrienne Savant ${ }^{2}$ \\ ${ }^{1}$ University at Buffalo Jacobs School of Medicine and Biomedical Sciences \\ ${ }^{2}$ Ann \& Robert H. Lurie Children's Hospital of Chicago
}

March 23, 2021

\begin{abstract}
CFTR (cystic fibrosis transmembrane conductance regulator) modulators are small molecules that directly change the CFTR protein, improving function of the CFTR chloride channel. Beginning in 2012 with the FDA approval of the first CFTR modulator, ivacaftor, this class of medication has had largely positive effects on many outcomes in people with cystic fibrosis (pwCF), including lung function, quality of life, and growth. There have been continued exciting developments in the current research on CFTR modulators, expanding beyond original studies. This first part of a three-part Cystic Fibrosis (CF) Year in Review 2020 will focus on research on CFTR modulators. Subsequent parts of the CF year in review will cover pulmonary and infectious inflammatory aspects, and the multisystem effects of CF in the 2020 literature. The review focuses on articles from Pediatric Pulmonology, but it includes articles from other journals that are of particular interest to clinicians. New developments in $\mathrm{CF}$ research continue to be brought forth to the $\mathrm{CF}$ community, deepening the understanding of this disease and improving clinical care.
\end{abstract}

\section{Introduction}

Cystic fibrosis transmembrane conductance regulator (CFTR) modulators improve the function of the CFTR chloride channel in epithelial cells throughout the body, thereby decreasing sweat chloride, and improving lung function and growth parameters in many people with $\mathrm{CF}$ ( $\mathrm{pwCF}$ ). The number of pwCF eligible for modulators has continued to increase over the past several years due to the addition of compounds to the class. Ivacaftor (iva) is a potentiator that increases the flow of chloride ions through the CFTR protein channel. After the approval of iva for the G551D mutation in 2012, the expansion of this drug for the use of other gating mutations followed. In subsequent years, the cystic fibrosis (CF) community saw the addition of two drugs for people with CF (pwCF) homozygous for F508del, lumacaftor/ivacaftor (lum/iva) in 2015, currently available for pwCF [?] 2 years old and tezacaftor/ivacator (tez/iva) in 2018, currently available for pwCF [?] 6 years old. Most recently, in October 2019 elexacaftor/tezacaftor/ivacaftor (ETI) was approved by the FDA in the US for patients [?] 12 years with at least one copy of F508del. During 2020, expansion has continued, with iva expanding to infants [?] 4 months of age ${ }^{1}$ and to an additional 59 mutations, for a total of 97 mutations, based on both clinical data and in vitro cell data ${ }^{2}$. While iva mutations were expanded, tez/iva eligibility was also increased by 127 mutations for a total of 154 responsive mutations, and ETI was broadened to an additional 177 mutations beyond F508del ${ }^{2}$.

This review will focus on the literature related to CFTR modulators published in 2020. Topics include the use of CFTR modulators in pwCF with FEV1 percent predicted (FEV1pp) $<40 \%$ or [?]90\%; in prior studies often these groups of patients were excluded. CFTR modulator effects on alternative mutations, worldwide populations, gender differences, and fertility are reported. The effect of CFTR modulators on other outcomes is also evaluated, including intestinal organoids, pancreatic function, and diabetes. Real world experience through case reports of side effects, adherence, and current cost effectiveness are examined. Finally, next steps for clinical trials in an environment where modulators have been developed for $\sim 90 \%$ of pwCF, but are 
not equally available, are highlighted. Research on other potential therapies is important so that all pwCF will have a highly effective therapy available to them.

\section{CFTR Modulator Effectiveness}

Recent iva studies

As introduced above, iva was expanded to children [?] 4 months, with the data published in the American Journal of Respiratory and Critical Care Medicine in 2020. Iva was found to be safe and well tolerated in children 4 to 12 months of age in a phase 3, multicenter, single-arm, 2-part study ${ }^{3}$. Twelve patients were included in the 4-day part A, to evaluate safety, pharmacokinetics and to demonstrate the proper dose for part B. Seventeen patients participated in the 24-week part B, to evaluate safety. Iva was found to be safe, with no cataracts detected, and lower rates of liver function test (LFT) elevation (1 infant in this study) compared to prior iva studies in 12-24 month and 2-5 year old children. Severe adverse event (SAE) rates were $8.3 \%$ ( $\mathrm{n}=1$ with thrombocytopenia felt to be due to omeprazole) in part A and $23.5 \%$ ( $\mathrm{n}=4$, bronchiolitis, cough, viral respiratory tract infection, and viral rash) in part B. None of the SAEs were felt to be related to iva. Pharmacokinetics, sweat chloride reductions, and maintenance of weight parameters were consistent with prior studies.

An open label extension study, including 3 multicenter trials, was published evaluating long term iva in non-G551D gating mutations ${ }^{4}$. Patients [?] 6 years of age were followed over 104 weeks; only 41 out of 121 people completed the trial, due to commercial availability of the drug. No additional safety concerns were revealed, only predictable adverse events (AEs) due to CF disease were found (such as pulmonary exacerbation (PEx), cough, headache, sinus congestion, increased sputum production, nasopharyngitis) with 2 SAEs possibly related to iva (PEx and sinusitis). Despite limited completion, efficacy was confirmed with mean absolute improvement in FEV1pp, increased body mass index (BMI), decreased sweat chloride, and increased CF Questionnaire-Revised (CFQ-R) respiratory domain scores.

Iva has been marketed in the United States since January 2012 and in the United Kingdom since July 2012, so long term follow up data is available. Using both the United States Cystic Fibrosis Foundation Patient Registry (US CFFPR) and the United Kingdom Cystic Fibrosis Registry (UK CFR), Higgins et al followed patients longitudinally from date of starting iva ${ }^{5}$. Annual cross sectional safety analysis was tracked over 5 years in a real world clinical environment, extending the work of this group's prior longitudinal ${ }^{6}$, and one time cross-sectional analysis ${ }^{7}$. The analysis demonstrated that iva had no new safety concerns. Lower risk of death, lung transplantation, hospitalizations, and PExs were seen and remained consistent across the 5 years analyzed.

\section{Open label extension ETI trial}

As described above, ETI was approved in October 2019 by the FDA for pwCF [?] 12 years old, and an open label extension study is still ongoing. An early interim analysis of the phase 3, open label extension trial results for ETI through week 24, in 506 participants was published ${ }^{8}$. Patients with F508del/minimal function $(\mathrm{F} / \mathrm{MF})$ or F508del/F508del (F/F) mutations were included, allowing those who were on placebo in primary studies ${ }^{9,10}$ to be provided open label ETI. Efficacy was similar to the primary phase 3 studies, with increases in FEV1pp by $14.9 \%$ and $12.8 \%$, in $\mathrm{F} / \mathrm{MF}$ and $\mathrm{F} / \mathrm{F}$ participants, respectively, when transitioning from placebo to $\mathrm{ETI}^{8}$. The reduction in annual PEx rate from 0.98 to 0.37 per year seen in the original $\mathrm{F} / \mathrm{F}$ 24-week phase 3 study was maintained in this extension trial. The rates of PEx were 0.3 events per 48 weeks in both the F/MF and the F/F groups. Sweat chloride, BMI and CFQ-R respiratory domain scores also demonstrated similar improvements compared to primary studies. Adverse events were similar to the primary studies. Only $7(1.4 \%)$ of AEs led to treatment discontinuation, including liver events $(\mathrm{n}=4)$, depression $(\mathrm{n}=1)$, rash $(\mathrm{n}=1)$, and tinnitus/contusion $(\mathrm{n}=1)$. Transaminase elevation above $3 \mathrm{x}$ normal occurred in only $36(7.1 \%)$ of the study population.

Advanced lung disease (ALD) (FEV1pp<40\%)

Initial phase 3 studies of CFTR modulators did not include pwCF with advanced lung disease (ALD), defined 
as FEV1pp $<40 \%$. A Danish single center observational study was performed in $21 \mathrm{pwCF}$ with severe lung disease [?]13 years old who were started on lum/iva as part of a compassionate use program and followed for 12 months $^{11}$. Criteria for inclusion were FEV1pp $<30 \%$ for adults or FEV1pp $<40 \%$ for children, or demonstration of 2 criteria including FEV1pp $<40 \%$ in adults or $<30 \%$ in children, FEV1pp slope less than $-2.5 \%$ in past 12 months, chronic difficult to treat pulmonary infections, or BMI z-score $<-2.0$ for children and BMI [?] 18 for adults. The median slope for FEV1pp decline was -2.6 in the year prior to treatment, compared to -2.1 during the year of treatment. FEV1pp improved, with a mean change of 3.1, 5.8, and 3.8\%, at 1, 6, and 12 months, respectively. Significant improvements in health-related quality of life and declines in sweat chloride were seen, although increases in BMI and cardiopulmonary exercise testing parameters did not reach significance. In a case control study by Tong $K$ et al , 72 F508del homozygous subjects over age 12 years, with FEV1 <40\%, from 7 Australian CF centers were treated with lum/iva and followed for 12 months ${ }^{12}$. The control group included 33 subjects with severe class 1 /class 2 CFTR mutations ineligible for lum/iva, matched for age, gender, and FEV1pp. The treatment group was found to have a lower rate of PEx requiring IV antibiotic treatment, with a mean rate of 1.49 per year (standard deviation (SD) 1.74), compared to a mean rate of 3.06 (SD 2.42) per year in the control group. Those on lum/iva also had prolonged time to first exacerbation, and increased rate of change in FEV1pp (0.107/month versus $-0.379 /$ month in controls). However, as will be reviewed below, there was a high rate of cessation of treatment of $32 \%$ over 12 months. These two studies suggested that lum/iva has clinical benefit in pwCF with advanced lung disease.

Although the initial ETI studies excluded those with FEV1pp $<40 \%$, there were a limited number of subjects (18 in ETI group versus 16 in placebo group) whose FEV1pp decreased to that level during the trial ${ }^{10}$. Those subjects on ETI did have a mean increase in FEV1pp of $15.2 \%$ above placebo (95\%CI 7.2 to 23.1\%) without a significant change in the rate of AEs compared to those with FEV1 $>40 \%{ }^{10}$. Further evaluation of patients with ALD was studied in a limited number of subjects in an Irish real-world study using a managed access program $^{13}$. Fourteen adults with CF and FEV1pp $<40 \%$ received treatment with ETI. The time of pre ETI data collection was variable and mean post-ETI follow up was $4.9 \pm 1.94$ months. ETI treatment led to improvement of mean FEV1pp from $27.3 \%$ at approximately 30 days to $36.3 \%$ at approximately day $60(\mathrm{p}<0.0001)$. Additional outcomes included: improvement of mean BMI from $20.7 \mathrm{~kg} / \mathrm{m} 2$ to $22.3 \mathrm{~kg} / \mathrm{m} 2$ $(\mathrm{p}<0.0001)$, and decrease in mean sweat chloride from $104.9 \mathrm{mmol} / \mathrm{l}$ to $64 \mathrm{mmol} / \mathrm{l}(\mathrm{p}<0.0001)$. PEx rates decreased significantly $(0.28 \pm 0.17$ exacerbations per month in the 12 months prior to ETI, versus $0.04 \pm 0.07$ exacerbations per month during the follow-up period of 4.9 months $(\mathrm{p}<0.001))$. ETI was well tolerated, with hospitalization due to distal intestinal obstructive syndrome $(n=1)$ and kidney injury unrelated to study drug $(\mathrm{n}=1)$, as the only significant AEs reported.

\section{FEV1pp [?] $90 \%$}

There has been a question as to whether pwCF with higher lung function would have similar benefits from CFTR modulators compared to those with lower lung function. A retrospective, observational study in the Netherlands included patients over age 6 years with FEV1pp[?] $90 \%^{14}$. Forty patients were followed before and after lum/iva, for 12 months. Results revealed a stable FEV1pp (-0.10\%), an increase in BMI $0.88 \mathrm{~kg} / \mathrm{m}^{2}(\mathrm{p}=0.001)$, and decreased PEx rate from 1.03 to $0.53 /$ person/year $(\mathrm{p}=0.003)$. CFQ-R scores improved by only $2.8 \%$ overall $(\mathrm{p}=0.004)$, which is not considered clinically significant, however, due to 22 out of 29 subjects improved and only 7 out of 29 remained stable or deteriorated. Interestingly, decline in sweat chloride occurred in all (mean difference of $27.3 \mathrm{mmol} / \mathrm{L}$ ), but was more pronounced in patients under age 18 (mean difference of $31.3 \mathrm{mmol} / \mathrm{L}$ ).

\section{Lung clearance index}

Lung clearance index (LCI) is an alternative research measure to FEV1pp. LCI is a measure of ventilation inhomogeneity. It can be found most easily using nitrogen washout from the lungs, and it is defined as the total sum of gas expired during the washout (cumulative expired volume), divided by the function residual capacity (FRC). Practically, it is the number of times the resting or end-tidal lung volume has to be "turned over" to clear or washout nitrogen $\left(\mathrm{N}_{2}\right)$ with $100 \% \mathrm{O}_{2}$. LCI is usually reported as $\mathrm{LCI}_{2.5}$, or washout until $1 / 40^{\text {th }}$ of the starting $\mathrm{N}_{2}$ end tidal concentration is reached. Normal LCI is less than 7.5 "turnovers" ${ }^{15}$. 
Shaw $M$ et al evaluated $\mathrm{LCI}_{2.5}$ in 49 subjects who were $\mathrm{F} 508$ del homozygotes, over 6 years of age, pre/post lum/iva treatment ${ }^{16}$. Although FEV1pp did not change with treatment, $\mathrm{LCI}_{2.5}$ decreased, which is evidence of clinical improvement in this measure. $\mathrm{LCI}_{2.5}$ decreased by 0.81 , demonstrating a $5.3 \%$ improvement at 1 month, with sustained decreases at 3 months and 6 months (cumulative decrease $0.77(5.9 \%$ improvement) and 0.67 (5.9\% improvement), respectively. $\mathrm{LCI}_{2.5}$ decrease was attenuated at 12 months with cumulative decrease 0.55 (4.3\% improvement) from baseline. Male gender, higher baseline $\mathrm{LCI}_{2.5}$, and younger age were independent predictors of initial improvement in $\mathrm{LCI}_{2.5}$. The clinical applicability of such a change is unknown as there is no acknowledged clinically significant difference for $\mathrm{LCI}_{2.5}$, however the authors state the improvement is similar to treatment effect seen with inhaled hypertonic saline in the preschool trial ${ }^{16,17}$.

Three other studies in 2020 studied $\mathrm{LCI}_{2.5}$ as an endpoint for CFTR modulator trials. A randomized, placebo-controlled, crossover study of 38 subjects with either the $3849+10 \mathrm{kbCT}$ or D1152H mutation compared $\mathrm{LCI}_{2.5}$ in those treated with iva versus placebo for 8 weeks ${ }^{18}$. In these subjects with mean baseline FEV1pp of 74 (SD 16.9), baseline LCI 13(SD 4.7), and 89.5\% of whom were adults, the difference in $\mathrm{LCI}_{2.5}$ between iva and placebo groups was $-0.66(95 \% \mathrm{CI},-1.10$ to -0.21$)$ at 8 weeks. There was one study dropout due to pregnancy in the placebo to iva treatment sequence. Otherwise, adverse events were similar in iva versus placebo, sweat chloride difference was $-9.2 \mathrm{mmol} / \mathrm{L}(-12.4$ to -5.9$)$, and FEV1pp improvement was $2.7(0.6-4.7)$ in iva versus placebo groups.

Nick JA et al contributed a phase 2, randomized, double-blind, placebo controlled, within patient crossover study using iva in $24 \mathrm{CF}$ subjects [?] 12 years (mean age 37.3 (SD 13.9) years) with residual function mutations ${ }^{19}$. Residual function in this study was defined as any one of the following: age [?] 12 years at diagnosis, having [?] 1 CFTR missense or splicing (not gating) mutation, screening sweat $\mathrm{Cl}$ [?] 80 $\mathrm{mmol} / \mathrm{L}$, or fecal elastase $(\mathrm{FE})>200 \mathrm{ug} / \mathrm{g}$ (indicating residual pancreatic exocrine function). Subjects were randomized to receive iva or placebo, followed by an 8 week open label period. The baseline mean FEV1pp of these subjects was $67.8 \%$ (SD 22.6), and baseline mean LCI was 10.6 (SD 3.1). After 2 weeks, there was an insignificant LCI difference of $-0.42(0.22)(\mathrm{p}=0.686)$ for iva versus placebo, and a significant increase in FEV1pp of 2.3 (SD 1) (95\% CI 0.4-4.1) for iva versus placebo. As part of the phase 3 open label extension part of this study, with iva compared to baseline, there was a -1.6 (SD 2.3) decrease in LCI, 4.7 (4.2) increase in FEV1pp $(\mathrm{p}<0.0001),-15.7 \mathrm{mmol} / \mathrm{L}$ decrease in sweat $\mathrm{Cl}, 0.5 \mathrm{~kg} / \mathrm{m}^{2}$ increase in BMI, and $1.8 \mathrm{~kg}$ increase in weight.

A phase 3, double blind, parallel group, 8 week study of tez/iva in fifty-four 6-11 year olds with CF, homozygous for F508del or heterozygous for F508del/residual function mutations, showed a significant decrease in $\mathrm{LCI}_{2.5}$ of 0.51 from baseline of $9.56(95 \% \mathrm{CI},-0.74 \text { to } 0.29, \mathrm{p}<0.0001)^{15}$. FEV1pp increased by 2.8 from baseline of 86.5 in the tez/iva group (95\% CI, 1.0-4.6). There were no SAEs in the study and only 3 subjects $(5.6 \%)$ in the tez/iva group had transaminase elevation [?] 3x normal. Sweat chloride decreased by $12.3 \mathrm{mmol} / \mathrm{L}$, and CFQ-R increased non-significantly by 2.3 points in the tez/iva group.

In these studies, $\mathrm{LCI}_{2.5}$ appeared to show some, but sometimes insignificant, improvements with iva, and tez/iva compared to placebo. $\mathrm{LCI}_{2.5}$ may be a useful parameter in future CFTR modulator studies, but further research is needed.

\section{Intestinal organoids}

Intestinal organoids are derived from rectal biopsies of individual patients. The biopsied cells form three dimensional structure of epithelial cells in vitro. As these intestinal cells have CFTR channels, in cells with functioning CFTR, the addition of forskolin will open the CFTR channels allowing for water uptake and the organoid will swell. As would be expected, in the absence of a modulator, the organoid will not exhibit forskolin-induced swelling If a modulator is present and effective, organoid swelling will be observed. Researchers have used organoids to test the effects of modulators on individual patients. Organoids include the specific cells of a patient in a three dimensional in vitro model, which can potentially be compared to the patient's individual clinical improvements with a specific modulator therapy. There have been two studies using organoids to study CFTR modulators in 2020. One group, mentioned above in the LCI endpoint 
section, studied the effectiveness of iva and compared the clinical and in vitroorganoid endpoints ${ }^{18}$. In the randomized placebo-controlled, crossover study of 38 subjects (37 completed), with either the $3849+10 \mathrm{kbCT}$ or D1152H mutation, intestinal organoids cultures were successfully established in 29 out of 33 biopsies, but only 25 intestinal organoid cultures met quality control standards. Swelling of organoids (indicating appropriate action of iva) occurred in 23 out of 25 patients, but there was no correlation (using Pearson correlation analysis) between the degree of clinical improvement (sweat chloride, LCI, FEV1pp) and the degree of swelling of the organoids for these subjects with the $\mathrm{D} 1152 \mathrm{H}$ or $3849+10 \mathrm{kbCT}$ mutation. Of note, the clinical improvements were small and measured over an 8 week period. In a separate study of patients with the A455E mutation, based on in vitro organoid data, 20 pwCF over age 12 were included in a randomized trial of lum/iva in the Netherlands with cross-over design for 8 weeks ${ }^{20}$. With lum/iva, FEV1pp did not change significantly (0.1\%). CFQ-R respiratory domain increased by 3.5 points, but this is not considered clinically significant. Sweat chloride decreased significantly by $-7.8 \mathrm{mmol} / \mathrm{L}, \mathrm{p}=0.004$, but this again may not show a biochemically relevant change, as the decreases in sweat chloride have been much greater with even lum/iva in F508del homozygotes, on the order of $20 \mathrm{mmol} / \mathrm{L}$. In vitro organoid response was seen but not correlated with sweat chloride or FEV1pp ${ }^{20}$, similar to the above findings. Both authors conclude that the use of organoids are of potential benefit to identify modulator responsive mutations, but may not predict the degree of response the patient will have in terms of clinical parameters like FEV1pp or sweat chloride ${ }^{18,20}$. One researcher postulated that a correlation between intestinal organoids and clinical phenotypes may not exist, as the clinical phenotypes took years to establish and may not be fully reversed by CFTR modulators, or may be impacted by other non-CFTR dependent factors ${ }^{21}$. It will be interesting to see the use of intestinal organoids for CFTR modulator research in the future.

\section{Cardiopulmonary exercise testing (CPET)}

Burghard et al. in the Netherlands examined effects of iva in 7 pwCF heterozygous for the S1251N mutation (1.2\% in Dutch population), over a median of 15 months ${ }^{22}$. Nutritional parameters changed, with BMI significantly increasing ( $19.9 \mathrm{~kg}$ to $21.2 \mathrm{~kg}, \mathrm{p}=0.03$ ), but BMI z-score, fat mass, and lean mass did not increase. Pulmonary function parameters changed with an increase in FEV1pp ( $81.7 \%$ to 97.7\%, p=0.02) and a decrease in RV/TLC (residual volume/total lung capacity) (31.5\% to 16.8\%, $\mathrm{p}=0.02$ ). No changes in resting energy expenditure were seen, but CPET indices improved, ppVO2peak (93.4\% to 80.7\%, $\mathrm{p}=0.01$ ), ppVO2peak $/ \mathrm{kg}(95.6 \%$ to $78.8 \%, \mathrm{p}=0.001)$, and change in VO2 over work rate $(10.7$ to $8.5 \mathrm{~mL} /$ watt, $\mathrm{p}=0.01)$, while other indices had no significant change ${ }^{22}$. In a separate study, 11 adults performed constant load cycling, with assessment of dyspnea and leg discomfort ${ }^{23}$. No change in endurance time, exertional dyspnea or leg discomfort occurred after one-month of lum/iva, but those who experienced reduction in leg discomfort showed improved endurance time.

\section{Nitric oxide}

Nitric oxide (NO) is a biomarker that can be assessed as nasal NO (nNO) or fraction of exhaled nitric oxide (FeNO), however neither has been routinely used as a biomarker in CFTR modulator studies. A study in the 1990s was done to establish baseline nNO in 19 healthy children, compared to 36 children with asthma and 8 children with $\mathrm{CF}^{24}$. The mean nNO levels were 239 (SD 20) parts per billion (ppb) in the controls, 254 (SD 17) ppb in the asthmatics, and 72 (SD 18) ppb in the children with CF. A separate study found that in adults (mean age 26.9 years), those with $\mathrm{CF}$ had a mean nNO of 520ppb (CI, 452-588), which was significantly lower than healthy, non-smoking adult controls (mean nNO 987ppb, CI 959-1015) ${ }^{25}$. In a recent study of treatment with iva, 8 patients with S1251N (class III gating mutation) with a median age of 16 (range 9-26) years, at one center in the Netherlands showed increases in measurements of median nNO from 220 to 462 ppb after 2 months, with no further increase in those followed for a year $(n=4)^{26}$. During this time when the $\mathrm{nNO}$ was increasing, the authors also demonstrated improvement in sinonasal symptoms, with reduction of CT sinus opacification (blinded Lund-Makay score), symptoms, and nasal endoscopic findings ${ }^{26}$.

Previous studies of FeNO have not always shown a significant difference in CF compared to healthy controls though there may be a trend toward lower levels ${ }^{27,28}$. A group in Toronto postulated that FeNO can be used as a clinical biomarker similar to nNO to determine the efficacy of CFTR modulators, as they state it is 
typically lower in pwCF compared to those without $\mathrm{CF}^{29}$. Their hypothesis was also based on two previous studies, which had shown that 4 weeks of iva increased FeNO levels in pwCF ${ }^{30,31}$. The mean increase in FeNO with iva in the two studies was from 8.5ppb (SD 5) to 16.2ppb (SD 15.5) in $15 \mathrm{pwCF}$, and from 6.6ppb (SD 2.19) to $11.8 \mathrm{ppb}$ (SD 4.97) in 5 pwCF, respectively ${ }^{30,31}$. The most recent two-site study in Toronto evaluated 20 patients on iva ( 8 pediatric/12 adult) and 14 pediatric patients on lum/iva ${ }^{29}$. The patients on iva had an increase in FeNO compared to their baseline after 4 weeks which was maintained for 24 months. The subjects on lum/iva had no change in their FeNO in the first year of treatment from baseline $10 \mathrm{ppb}$ (range 8-15 ppb); however, some patients $(\mathrm{n}=5)$ showed improvement at 2 year follow up (median increase $9 \mathrm{ppb}, 95 \%$ CI 2.8-15.6ppb, $\mathrm{p}=0.02$ ). The use of both $\mathrm{nNO}$ and $\mathrm{FeNO}$ as biomarkers in future studies of modulators could be considered, but their widespread use would require more patient data and investigation.

\section{Alternative mutations}

Each modulator is approved for specific mutations, but exploration of effectiveness in other mutations occurs. Sometimes, specific modulators are found to not be effective for specific mutations, which is very useful negative data. Tez/iva was examined in pwCF heterozygous for F508del and a minimal function mutation in a randomized, double blind, placebo controlled, parallel group, phase 3 trial in patients [?]12 years of age. FEV1pp did not improve ${ }^{32}$. Specifically, the trial had predetermined criteria for futility. Predetermined levels for FEV1pp were met at 12 weeks; the treatment difference for FEV1pp was $1.79 \%$, which was below the predetermined futility boundary of $2.5 \%$. The within tez/iva group improvement for absolute FEV1pp was $1.53 \%$, again less than the predetermined level of $1.75 \%$, thus the trial was stopped for futility. No differences in BMI, CFQ-R respiratory domain, or PEx rate were seen ${ }^{32}$. This research highlights that tez/iva is not effective for pwCF with F508del/minimal function mutations. In patients heterozygous for F508del and a gating mutation, a multicenter, international, randomized, double blind, parallel group, phase 3 trial compared tez/iva to iva alone in 153 patients over age 12 years, over 8 weeks ${ }^{33}$. No difference in FEV1pp, sweat chloride or CFQ-R respiratory domain were seen, though the reduction of sweat chloride level was lower with the combination treatment compared to iva alone (-5.8 difference). The conclusion was that tez/iva did not demonstrate any additional clinical efficacy over iva alone, but it was safe and well tolerated.

\section{Pancreatic status}

One question that research has tried to answer regarding CFTR modulators is whether or not they can improve or reverse pancreatic insufficiency, since it is affects $85 \%$ of pwCF and the pathophysiology begins in utero. Munce et al described 3 patients who had alterations in pancreatic function with iva. Each of the patients had FE measurements that were low (patient one: $40 \mathrm{mcg} / \mathrm{g}$ at 2 weeks of age, patient two: 50 $\mathrm{mcg} / \mathrm{g}$ at 1 month and patient 3: $61 \mathrm{mcg} / \mathrm{g}$ at 3 months). All were started on iva at varying ages: 4 years, 6 years and 7 years, respectively, and FE levels were in the pancreatic sufficient range after treatment for 2 years in patients 1 and 2 , and after 4 months in patient $3^{34}$. Hutchinson et al performed a retrospective clinical review of 18 children in Ireland, with the G551D mutation, who had started on iva over the last 11 years at their center: FE increased in all but 1 person, with 11 out of 18 having FE levels $>200 \mathrm{ug} / \mathrm{g}$ and having discontinued pancreatic enzymes without abdominal complaints with a median follow up of 12 months (range 8-22 months) ${ }^{35}$. Those who achieved pancreatic sufficient levels were more likely to have had detectable $\mathrm{FE}$ at baseline $(8 / 11$ versus $0 / 7, \mathrm{p}<0.01$ ), less likely to have a second severe mutation (F508del or minimal function: $2 / 11$ versus $6 / 7, \mathrm{p}=0.01$ ), and more likely to be younger upon starting iva (4 versus 8.6 years, $\mathrm{p}<0.001)^{35}$. Similarly, a letter to the editor in Pediatric Pulmonology from Wright $B$ et al described a report of an F508del homozygous patient with an FE of $65 \mathrm{mcg} / \mathrm{g}$ at 3 weeks of age, who started lum/iva at age 6 and had repeat FE measurements at age 9 in the sufficient range of 366 and $348 \mathrm{mcg} / \mathrm{g}^{36}$. Smith H et al in Pediatric Pulmonology wrote a letter to the editor highlighting a case in an older child with a FE $<15 \mathrm{mcg} / \mathrm{g}$ at 2 years of age who started on iva at 14 years of age, who then became non-adherent to his pancreatic enzyme replacement therapy with no signs or symptoms of malabsorption. Repeat FE at age 17 was $263 \mathrm{mcg} / \mathrm{g}^{37}$. This case is relevant as it suggests a patient may become pancreatic sufficient if a CFTR modulator is started in the teenage years, as opposed to earlier in childhood when pancreatic function is 
more likely to be impacted. Measurement of pancreatic function throughout childhood on CFTR modulators is an important parameter to assess, especially with the use of the highly effective modulator ETI.

\section{Diabetes}

The impact of CFTR modulators on the development or control of diabetes is a pertinent area of study as CF related diabetes (CFRD) affects up to $20 \%$ of adolescents and $50 \%$ of adults with $\mathrm{CF}^{38}$. Many pwCF who do not yet have CFRD have impaired glucose tolerance (IGT). Part of the pathophysiology of IGT and CFRD involves decreased insulin secretion, insulin resistance and hepatic glucose control abnormalities, along with other mechanisms of insulin insufficiency such as destruction of the pancreas, islet cell inflammation, and oxidative stress ${ }^{39}$. In past studies of those with the G551D mutation, iva improved insulin secretion $^{38}$. Therefore, studies have been undertaken to evaluate if lum/iva improves glucose tolerance in F508del homozygotes. A prospective, observational study in France, examined the effect of lum/iva on glucose tolerance abnormalities in pwCF between ages 12-61 years (average 24 years). At baseline, 78\% of 40 patients had IGT, and $22 \%$ had newly diagnosed CFRD, while patients with fasting hyperglycemia, requiring insulin therapy or, with normal glucose tolerance (NGT) were excluded ${ }^{39}$. After 1 year of lum/iva treatment, based on 2-hour glucose levels in the oral glucose tolerance test (OGTT), 57.5\% improved their glucose tolerance, and $42.5 \%$ had no change $(\mathrm{p}<0.001)$. Overall, after 1 -year lum/iva, $50 \%(\mathrm{n}=20)$ had NGT, $40 \%(n=16)$ had IGT and $10 \%(n=4)$ had CFRD. Specifically, out of those with newly diagnosed CFRD $(\mathrm{n}=9)$, after 1 year of lum/iva, 2 had NGT, 3 had IGT and 4 continued to have CFRD. Out of 31 subjects with IGT, after 1 year of lum/iva, 18 had NGT, 13 had IGT and 0 developed CFRD. Additionally, in the entire cohort, the 2-hour glucose levels decreased from $171 \mathrm{mg} / \mathrm{dL}(153-197 \mathrm{mg} / \mathrm{dL})$ to $139 \mathrm{mg} / \mathrm{dL}(117-162$ $\mathrm{mg} / \mathrm{dL})(\mathrm{p}<0.001)$. HemoglobinA1c, C-peptide, fasting and one hour glucose levels, and insulin levels were unchanged.

A separate study evaluated glucose alterations in 39 subjects, aged 12-51 years, prior to and 3, 6, and 12 months after initiation of lum/iva ${ }^{38}$. At one year post treatment, the mean values comparing baseline, $3-$, 6 -, and 12-month values did not differ for any of the parameters, including fasting glucose levels $(\mathrm{p}=0.74)$, 2-hour glucose levels $(\mathrm{p}=0.26)$, glucose area under the curve $(\mathrm{p}=0.67)$, insulin area under the curve $(\mathrm{p}=0.82)$, and peak insulin levels $(\mathrm{p}=0.33)$. Overall, there was no significant improvement with lum/iva in any of the glucose tolerance categories. Out of those with CFRD $(n=15), 2(13 \%)$ improved and $13(87 \%)$ stayed the same. In those with NGT $(\mathrm{n}=9), 6(67 \%)$ stayed the same and $3(33 \%)$ worsened. In those with indeterminate glycemia (defined as normal fasting and 2 hour, but elevated mid OGTT glucose) ${ }^{40}$ and IGT $(\mathrm{n}=15), 7(47 \%)$ improved, $5(33 \%)$ stayed the same and $3(20 \%)$ worsened. No changes were seen in fasting or 2-hour glucose levels, area under the curve for glucose or insulin, time to peak insulin, or C-peptide levels. The results of these two trials show benefit with iva and lack of benefit with lum/iva in impacting OGTT results. However, the minimal effects and the differential responses show that further studies will be needed to truly understand the impact of different CFTR modulators on glucose tolerance.

\section{Sex Differences}

Researchers are looking at sex differences in CFTR modulator response, as it is known that females with CF may have reduced median life expectancy and other risk factors for worsened disease, compared to males. In the GOAL study (G551D observational study) of iva, a new analysis in pwCF [?] 6 years of age, with at least one G551D mutation, differences in outcomes beyond FEV1pp were examined by sex ${ }^{41}$. In 144 patients, with a mean age of 21.6 years, the key findings were that sweat chloride declined more in females after 3 months of treatment $(-55.5 \mathrm{mEq} / \mathrm{L}$ versus $-48.8 \mathrm{mEq} / \mathrm{L}, \mathrm{p}=0.045)$, and the reduction in sweat chloride correlated with baseline weight in females. PExs declined significantly in females (1.7 to 0.9 PEx/yr, p=0.024), compared to a non-significant decline in males (1.1 to $0.8 \mathrm{PEx} / \mathrm{yr}, \mathrm{p}=\mathrm{NS})$. At an individual level, more females had a decline in PEx rate (46.3\% versus $27.3 \%, \mathrm{p}=0.024)$. When exploring results based on age, patients $<18$ years had similar response in males and females for weight, sweat chloride, but for those [?] 18 years, women had lower mean baseline weight, and a greater sweat chloride reduction with iva. Understanding disease differences in males and females with $\mathrm{CF}$ is an important part of adequately treating this disease. Examining differential effects of CFTR modulators based on gender will be imperative, to assure that the 
therapeutic benefit is adequate in both sexes.

Pregnancy and Fertility

Similar to looking at gender differences, investigating the impact of CFTR modulators on pregnancy and fertility is a relevant topic that impacts the increasing number of healthier adults with CF. The effects of CFTR modulators on fertility and pregnancy are beginning to be reported. In a patient experience interview, a pregnant woman reported that the provider team was neutral or encouraged discontinuation of modulator treatment stating "They [health-care providers] weren't sure at that point if it [lum/iva] was safe or not safe. There wasn't any information on it so they said, 'It's up to you" "42. As both infertility and subfertility are common in CF, many have seen an increase in pregnancies with modulator use. In a 2-center retrospective chart review from October 2019 through May 2020, 14 females on ETI became pregnant at a median of 8 weeks (range 1-17 weeks) after starting therapy ${ }^{43}$. Of these 14 patients, 7 were previously trying to conceive, but had a history of subfertility or infertility. The other 7 had not been and were not actively trying to conceive, but only 2 were using condoms and 1 natural family planning, while 4 were not using any contraception. This study suggests that ETI may improve fertility in women with CF. ETI was continued in 10 out of 14 women despite the lack of clinical trials during pregnancy ${ }^{43}$. In a 2018-2019 international survey of 31 adult CF centers in the US, UK, Australia, Israel and Europe, 64 pregnancies were identified in 61 women on modulators: 31 pregnancies in 28 women on iva, 26 pregnancies on lum/iva, and 7 pregnancies on tez/iva ${ }^{44}$. There were numerous maternal complications, mainly as expected for a patient with CF. However, there were 2 maternal complications reported by the clinician responding to the survey as due to modulators (lum/iva): PEx and post-partum acute myelogenous leukemia. As PEx is common in CF and there have been no associations between modulators and hematologic malignancies, the authors believe these complications may not have been related to lum/iva. The pregnancies resulted in a total of 60 live births, 3 miscarriages ( 2 on iva, one on tez/iva) and one termination for maternal health concerns. Although some infants had complications, none were felt to be due to modulator use and no infants who were formally examined (6 babies) were found to have cataracts. No reports of complications during breastfeeding occurred (25 infants were breastfed total $)^{44}$. Further research and counseling on possible increased reproductive potential with CFTR modulators is needed. The CF Foundation Therapeutics Development Network established a working group on Women's Health, which through an upcoming observational study of women and pregnancy outcomes (MAYFLOWERS- Maternal and Fetal Outcomes in the Era of Modulators) ${ }^{45}$, will help gain more insights.

\section{Side effects}

Side effects of CFTR modulators reported in case reports in 2020 are presented in Table 1. Rash was reported in two separate $\operatorname{cases}^{46,47}$, and has been reported in the past with ETI. Catamenial hemoptysis ${ }^{48}$ and testicular pain ${ }^{49}$ were also reported.

\section{CFTR Modulator Interactions}

The interaction of CFTR modulators on the metabolism of other drugs such as tobramycin is a salient point to consider, given the progressive nature of CF pulmonary disease and the likely need for IV antibiotic treatment for PEx despite having access to a CFTR modulator. Albricht JC et al reported a retrospective evaluation of 34 patients on modulator therapy (iva, lum/iva, tez/iva) to evaluate for alterations in tobramycin pharmacokinetics and nephrotoxicity ${ }^{50}$. Data obtained during inpatient admission both prior to modulator use and at least 2 weeks post modulator use, was assessed for patients 2-18 years of age. The median values did not differ for pre/post CFTR modulator elimination rate $(\mathrm{Ke})\left(0.41 \mathrm{hr}^{-1}\right.$ versus $0.39 \mathrm{hr}^{-1}$, $\mathrm{p}=0.5)$, volume of distribution $(\mathrm{Vd})(0.33 \mathrm{~L} / \mathrm{kg}$ versus $0.34 \mathrm{~L} / \mathrm{kg}, \mathrm{p}=0.99)$, or peak tobramycin concentration (Cmax) $(28.9 \mathrm{mcg} / \mathrm{mL}$ versus $27.2 \mathrm{mcg} / \mathrm{mL}, \mathrm{p}=0.22)$. Nephrotoxicity (measured by the pRIFLE criteria, an increase in serum creatinine by [?]50\% from baseline) was present in 9 (26.5\%) of patients pre CFTR modulator and $6(17.6 \%)$ of patients post modulator $(\mathrm{p}=0.25$, NS). Thus, CFTR modulators did not seem to affect the elimination rate for IV administered tobramycin, and no increased nephrotoxicity was seen.

Tobacco smoke exposure has negative effects on pulmonary function, and tobacco smoke avoidance is ad- 
vised in all patients with CF. The effect of tobacco smoke on lung function improvement seen with CFTR modulators is unknown. In a retrospective analysis of the CFF Registry from 2016-2018, a comparison between pediatric patients who were exposed to tobacco smoke compared to unexposed individuals evaluated difference in FEV1pp after initiation of tez/iva ${ }^{51}$. At baseline, smoke exposed tez/iva treated patients had a $7.6 \%$ lower mean FEV1pp compared to smoke unexposed tez/iva treated patients. At 2 years of tez/iva treatment, the FEV1pp of smoke exposed patients was $8.8 \%$ lower than smoke unexposed patients. In those not exposed to tobacco smoke, with tez/iva FEV1pp increased by $1.2 \%(87 \%, 95 \%$ CI $86.3 \%-87.7 \%$ versus $85.8 \%, 95 \%$ CI $85.2 \%-86.3 \%$ at baseline). This was definitely a minimal increase, which is slightly lower compared to other studies with tez/iva. However, among patients exposed to tobacco smoke, those treated with tez/iva did not have improved FEV1pp compared to those who did not receive tez/iva $(82.9 \%, 95 \% \mathrm{CI}$ $81.8 \%-83.9 \%$ versus $82.5 \%$, CI $81 \%-83.2 \%$ ). Therefore, tobacco smoke eliminated the small improvement in FEV1pp seen with tez/iva treatment. The effect of tobacco smoke on the improvements in lung function seen with the highly effective modulator, ETI has not yet been studied, but would be interesting to explore to see if smoke exposure attenuates the significant benefits seen in FEV1pp with ETI.

\section{Worldwide outcomes}

Real world studies, collected outside of randomized studies, may give added information about CFTR modulators in populations that are not identical to those in whom the randomized clinical trial was performed, such as in different countries or ethnic populations. One retrospective observational study done in Greece, looked at lum/iva, to see if the population had similar improvements in lung function compared to initial $\mathrm{RCTs}^{52}$. In this study, 52 patients eligible for lum/iva were studied in an observational, retrospective study over 12 months. The FEV1pp increased by $2.3 \%$, and using a multivariate longitudinal model there was an improvement in the rate of decline of lung function. The increase in FEV1pp was similar to the rate seen in the lum/iva pivotal phase 3 study published in 2015.

PwCF clinically prescribed lum/iva in 2016 were studied in a "real world" manner in 47 centers in France, examining differences in outcomes between those who took continuous treatment, intermittent therapy, or discontinued therapy ${ }^{53}$. In a total of 845 patients, over age 12 years, who were started on lum/iva, $12 \%$ of the patients did not start at full dose, due to suspected drug interactions $(\mathrm{n}=74)$ or other miscellaneous reasons $(\mathrm{n}=26)$, which were not specifically described in the paper. The average FEV1pp improvement at 12 months was $2.7 \%+-8.86 \%(\mathrm{n}=821, \mathrm{p}<0.001)$. Those with continuous usage $(\mathrm{n}=631)$ had increased FEV1pp 3.67+$8.62 \%(\mathrm{p}<0.001)$, and a more robust increase was seen in adolescents. For those with intermittent usage of lum/iva (stopped and restarted, $\mathrm{n}=45$ ), FEV1pp trended toward improvement $(+2.36+-8.47, \mathrm{p}=0.09)$. For those who discontinued treatment, FEV1pp trended down $(-1.36+-9.03 \%, \mathrm{p}=0.07)$. Additional outcomes with lum/iva included: increases in weight and BMI, decreases in use of IV antibiotics, no changes in vitamin A, E or D levels, and no changes in HbA1C (hemoglobin A1C) in those with CFRD. Despite differential patterns of taking the lum/iva therapy, the improvements in FEV1pp were similar to the initial phase 3 studies.

The Italian CF registry was reviewed in a study looking at clinical parameters in patients with gating mutations (GM) compared to F508del homozygotes; GMs were found in 186 (3.3\%) compared to 1005 $(21.5 \%)$ F508del homozygotes among 5552 patients in the registry ${ }^{54}$. Only $0.06 \%(n=7)$ of the Italian CFTR mutations were G551D, which is substantially lower than other populations. In the study, there was an improvement from 2012 to 2017 in patients with GMs in terms of lung function (FEV1pp increased from $73.6 \%$ (SD 26.6\%) to 79.8\% (SD 27.3\%), compared to no change in the F508del homozygotes (FEV1 pp $77.1 \%$ (SD24.1\%) compared to $75.2 \%$ (SD 24.7\%). In those with GMs, BMI improved and there was decreased diabetes, while these parameters did not improve in the F508del homozygotes. However, the Italian CF registry itself does not have documentation of whether or not the patients were on iva. Therefore, as part of the study, a survey of CF Centers in Italy on modulator use was performed after 2014/2015, when iva first became available in Italy. The percentage of patients treated with iva steadily increased from $4 \%$ in January 2014 to $75 \%$ at the end of 2017 , and the authors suggest this likely led to the changes seen in the GM patients in the Italian CF registry. 


\section{Adherence}

CFTR modulator use patterns, as seen above, are not always uniform. It is relevant to study adherence in the case of modulators to assure efficacy and to evaluate side effects. In the above real-world study in France of lum/iva, out of 845 subjects, $154(18.2 \%)$ discontinued the medication at a median of 90 days (interquartile range 25-179 days $)^{53}$. Of those who took full dose, $17.3 \%(129 / 745)$ discontinued, while $25 \%(25 / 100)$ at reduced dose discontinued ${ }^{53}$, compared to $4.2 \%$ of patients who took lum/iva in the phase 3 safety/ efficacy trial $^{55}$. The primary reason $(48.1 \%)$ for discontinuation was respiratory events (chest tightness, dyspnea, bronchospasm, increased cough/sputum, hemoptysis, and pneumothorax). Non- respiratory reasons such as diarrhea, abdominal pain, myalgia, fatigue, headache, depression, metrorrhagia, elevated LFTs, tachycardia, and rash were the next most frequent at $27.9 \%$. Subjects were more likely to discontinue lum/iva if they were adults, their FEV1pp was [?]40\%, or they had a greater number of IV antibiotic courses the previous year. The Australian study mentioned above of F508del homozygotes with FEV1pp [?] 40\% demonstrated that despite benefits of reduced PEx and rates of lung function decline, 55\% of 105 subjects had chest tightness or dyspnea and $32 \%$ discontinued treatment ${ }^{56}$.

In contrast, a retrospective pharmacy refill history study in France of 96 patients showed very high adherence to therapy, with the mean proportion of days covered (PDC) $96 \%$ at 6 months, and $91 \%$ at 12 months ${ }^{57}$. However, the PDC measure is calculated by the total number of medication days divided by the number of days in the given period, and high rates may reflect only filling or over-filling the medication, not actually taking it. The proportion of adherent patients, defined as PDC [?]0.80, was $89 \%(\mathrm{n}=86)$ and $83 \%(\mathrm{n}=80)$ at 6 and 12 months, respectively. Of those who were non-adherent, the majority were in the 18-25-year-old group (56\%) compared to patients 26-35-year-old $(6.3 \%),>35$ years old $(6.3 \%)$, and the 12-17-year-old $(31 \%)$. The generalizability of this study is limited by the overestimation of adherence using the PDC measure, as well as by the small sample size.

Adherence to lum/iva was difficult for some due to respiratory side effects, and one study was performed to assure this population would not have similar respiratory side effects with tez/iva. A phase 3b, randomized, double blind, placebo-controlled, parallel group, multicenter trial of placebo versus tez/iva enrolled subjects who had discontinued lum/iva due to [?]1 respiratory sign or symptom considered related to treatment ${ }^{58}$. Subjects were pwCF [?]12 years old, homozygous for the F508del-CFTR mutation with FEV1pp of [?]25\% and [?] $90 \%$ and followed for 56 days of treatment and 28 days safety follow up. Out of 97 participants, 50 received tez/iva and 47 received placebo. The mean difference in FEV1pp with tez/iva versus placebo was $2.7 \%$ (95\% CI: 1-4.4). The incidence of respiratory related adverse events was 7 (14\%) in the tez/iva group versus $10(21.3 \%)$ in the placebo group. Only $1(2 \%)$ respiratory event in the tez/iva group versus $4(8.5 \%)$ respiratory events in the placebo group were thought to be related to treatment. Two patients in each group (4\%) discontinued study drug. Overall, tez/iva was well tolerated without respiratory related treatment adverse events or discontinuation in patients with previous respiratory related symptoms due to lum/iva, many of whom had FEV1pp [?]40\%. This suggests tez/iva is safe, and due to absence of significant respiratory related symptoms, may be better tolerated than lum/iva in those with initial respiratory symptoms and thus result in better adherence to therapy.

\section{Cost-effectiveness of CFTR Modulators}

Thus far, few studies have demonstrated cost-effectiveness for CFTR modulators. This year, a retrospective study in Ireland of a national pharmacy claims database found that although there was an eight-fold increase in prescribing for all modulators, there was no reduction in other chronic therapy medication prescriptions ${ }^{59}$. Specifically, for iva, there was a reduction in patients receiving symptomatic treatments (dornase alfa and inhaled tobramycin, $\mathrm{p}<0.001$ ), but no reduction was seen for lum/iva; however, an increase in colistimethate $(\mathrm{p}=0.01)$ was seen. Based on this pharmacy data alone, and no inclusion of other resource utilization such as hospitalization, cost effectiveness was not found for iva and lum/iva while tez/iva remains uncertain. A simulation model in the US, evaluated the economics of iva use over a lifetime, starting at age 6 months, compared to best supportive care alone ${ }^{60}$. Iva was found to have improved quality-adjusted life years (QALYs) over supportive care (22.92 vs 16.12$)$ but cost approximately $\$ 6.4$ million more in total lifetime 
costs. Scenario projections demonstrated that best supportive care was the most cost-effective treatment up to a willingness to pay $\$ 1$ million, well above the commonly accepted willingness to pay threshold of $\$ 500,000$ where iva's cost effectiveness was $0 \%$.

\section{Trial Development}

Beyond approval, there continues to be a proportion of the CF community that does not have a specific CFTR modulator therapy. Globally, some countries may have immediate access, and others have no access. Some of the lack of access may be due to the specific mutations within a population. In Turkey, for example, only 122 patients $(9 \%)$ of $1488 \mathrm{CF}$ patients in their registry are eligible for iva and $539(27.2 \%)$ for ETI, just based on the mutations present in their population ${ }^{61}$. Similarly, in the Canadian registry, patients diagnosed in adulthood had reduced eligibility for modulators at $83 \%$, meaning that there are no CFTR modulators for the rarer mutations seen in some individuals with $\mathrm{CF}$ who have are diagnosed into adulthood ${ }^{62}$. The first step to highlighting the rarer mutations that do not have access to modulators is to accurately describe the populations of individuals with $\mathrm{CF}$ in studies. McGarry points out in two letters to the editor (Lancet and NEJM), that race and ethnicity were not included as part of the demographic information for the two phase 3 large, randomized controlled trials of ETI, despite a known increased burden and more severe pulmonary disease in minority patients ${ }^{63,64}$.

In addition to the need for other CFTR modulators to impact the entire CF population, there is a continued therapeutic need for the development of medications for infection, inflammation, and mucus clearance, among other areas. The variation in access to modulators, the inadequate therapeutic success in various populations, and the need for new trial designs is leading to a shift in preparations for future clinical trials. Several worldwide meetings among clinical trial experts took place to discuss these concerns and develop recommendations as well as extend collaborations, identify areas for harmonization, and gain efficiencies to promote ethical, feasible, and credible study designs amidst the changing landscape of CF care ${ }^{65-68}$. Further details of this work can be found in the mentioned references.

Furthermore, patient and clinician experience will be important in the selection of CFTR modulators, as well as on the selection of treatments to continue to reduce treatment burden in $\mathrm{CF}^{69,70}$. In a survey of 60 adults and 30 caregivers, regarding what influenced patients' decision to start a modulator, the most impactful influence was providers/care team, followed by parents and then the individual themselves ${ }^{69}$. Surprisingly, social media only accounted for a small amount of influence at $13 \%$. A separate survey of pwCF, families and acquaintances as well as clinicians, inquired about interest in withdrawal of therapies in patients on CFTR modulators $^{70}$. Overwhelmingly, there was widespread support by $80 \%(541 / 645)$ of the community, and $95 \%$ (206/218) of clinicians. Moreover, this type of study was also surveyed as feasible, as $83 \%(299 / 359)$ of the community reported not having reduced or stopped taking their other chronic medications. The SIMPLIFY trial, which is under way, will test the effects and safety of stopping inhaled hypertonic saline or dornase alfa in teens and adults with CF who are also taking the triple-combination modulator, ETI ${ }^{71}$.

To work toward therapy for all mutations that cause CF, research has continued. One such area is premature stop codons, a group not currently treatable with modulators. Ataluren is a read- through medication that underwent phase 3 studies, without success, however it was noted that those patients who were not on inhaled aminoglycosides had a treatment efficacy signal. Therefore, a randomized, double blind, placebo-controlled trial, in patients over age 6 with FEV1pp between $40 \%$ and $90 \%$, who were not on inhaled aminoglycosides, was conducted in 279 enrolled patients over 48 weeks $^{72}$. Both the treatment and placebo group had a decline in FEV1pp with no difference between the groups. Furthermore, BMI, PEx rates, and respiratory quality of life did not differ.

Further exploring ataluren effect, using N-of-1 trial design, two patients (31-year-old with W1282X/G542X and a 32-year-old with $\mathrm{W} 1282 \mathrm{X} / \mathrm{W} 1282 \mathrm{X}$ ) had therapy with combined ataluren and ivacaftor ${ }^{73}$. In the first patient, iva was added to ataluren for 2 separate 2 week periods and compared to ataluren alone and iva alone. No change in sweat chloride, FEV1pp, or BMI was seen on any combination, but iva alone had some modest benefit in nasal potential difference (NPD). The CFQ-R respiratory domain improved during both 
ataluren/iva and iva alone time periods. For the second patient, who was already on iva, ataluren was added for approximately 11 months. There was a slight increase in BMI with combination therapy $\left(19.8 \mathrm{~kg} / \mathrm{m}^{2}\right.$ versus $19.3 \mathrm{~kg} / \mathrm{m}^{2}$ in iva alone) and improvement in NPD $(-22.5 \mathrm{mV}$ versus $-6.7 \mathrm{mV}$ in iva alone). Higher CFQ-R scores were seen on iva alone (88.9 versus 78.9). No changes were seen in FEV1pp or sweat chloride. The authors concluded that the results were mixed.

In a trial mentioned above in the LCI section, one group performed N-of- 1 studies in 24 pwCF, over age 12 years, with at least one missense or splicing mutation, using a randomized, double blind, placebo-controlled, within patient, crossover study design examining iva benefit ${ }^{19}$. After 2 weeks of iva, FEV1pp had a treatment difference of $2.3 \%$; after 8 weeks the FEV1pp treatment difference was $4.0 \%$. Additional outcomes showed improved LCI, sweat chloride, weight, and BMI.

A study in Germany attempted to use GLPG2737, a novel CFTR corrector, in a phase 2a, randomized, double blind, placebo controlled, parallel group study comparing 14 patients who had add on of GLPG2737 to lum/iva to 8 patients on lum/iva alone over 28 days $^{74}$. The primary outcome was met, with reduced sweat chloride mean difference of $-19.6 \mathrm{mmol} / \mathrm{L}(\mathrm{p}=0.0210)$. Secondary exploratory outcomes, FEV1pp and CFQ$\mathrm{R}$ respiratory domain, did not significantly differ, however the study was not powered to find differences. The authors posit that drug interactions between GLPG2737 and lum led to lower exposure to GLPG2737 than predicted from in vitro studies, possibly accounting for the lower FEV1pp findings.

Another new modulator, icenticaftor (QBW251) underwent a randomized, double blind, placebo-controlled, dose escalation study over 14 days in healthy volunteers followed by $\mathrm{pwCF}^{75}$. Icenticaftor, in combination with lum has shown superior in vitro effect in sustaining membrane expression and function compared to iva, therefore is postulated to have improved effect. This study of monotherapy with icenticaftor showed it was well tolerated, and in patients with class 3 or 4 mutations $(\mathrm{n}=24)$, a treatment difference in $\mathrm{LCI}_{2.5}$ of -1.13 , FEV1pp of $6.46 \%$, and sweat chloride of $-8.36 \mathrm{mmol} / \mathrm{L}$ was seen. However, in patients homozygous for F508del $(n=25)$, the study was stopped at interim analysis due to no treatment difference $\left(\mathrm{LCI}_{2.5} 0.48\right.$ and FEV1pp of $0.53 \%)$.

Working to find a therapy that can be applied to any mutation, antisense oligonucleotides have been under investigation. Eluforsen was evaluated in a randomized, double blind, placebo-controlled, dose escalation, phase $1 \mathrm{~B}$ study in adults with CF and FEV1pp [?] $70 \%{ }^{76}$. Eluforsen, given via nebulization for up to 4 weeks, was found to be well tolerated with no dose limiting toxicities, and no related adverse events. As variable doses were given, exploratory efficacy outcomes varied. Patients with FEV1pp [?]90\% had a difference of 8\% compared to placebo at $6.25 \mathrm{mg}$ dosing and $10.9 \%$ at $12.5 \mathrm{mg}$ dosing, although this encouraging efficacy signal should be interpreted cautiously as there were small numbers of patients ( $\mathrm{n}=34,36$ in 2 cohorts). CFQ- $\mathrm{R}$ respiratory symptom score was statistically significantly improved (range difference to placebo of 12.91 to 19.13 points) in three doses, however sweat chloride values did not change.

\section{Conclusion}

The year 2020 has brought many exciting developments in the field of CFTR modulators, including the use of currently available modulators for other mutations, and exploration of the efficacy of modulators on alternative endpoints, such as LCI, nitric oxide, cardiopulmonary exercise testing, and intestinal organoids. Special populations studied included those with FEV1pp $<40 \%$ and FEV1pp[?]90\%. Adherence and real-world studies were reviewed. The effects of CFTR modulators on pancreatic function, diabetes, sex differences and fertility were also reported in various studies. Due to the cost analysis and worldwide outcome data suggesting differential efficacy and eligibility for currently available CFTR modulators, there is a continued need for new therapeutic avenues and unique research designs. Real world evidence and patient involvement in research priorities will continue to be important, as ways to increase access to appropriate and effective therapy is the overarching goal of CF care.

Table 1: Side Effects of CFTR Modulators Reported in 2020 


\begin{tabular}{|c|c|c|c|c|}
\hline & $\operatorname{Rash}^{46}$ & $\operatorname{Rash}^{47}$ & Hemoptysis ${ }^{48}$ & $\begin{array}{l}\text { Testicular pain } \\
49\end{array}$ \\
\hline Modulator & ETI & Lum/iva ETI & Lum/iva & $\begin{array}{l}\text { ETI and } \\
\text { tez/ivaETI }\end{array}$ \\
\hline Genetics & F508del/R347H & F508del/F508del & F508del/F508del & $\begin{array}{l}\text {-F508del/F508del } \\
(\mathrm{n}=4) \\
-\mathrm{F} 508 \mathrm{del} / \mathrm{c} .2921- \\
2930 \mathrm{ins} 10(\mathrm{n}=1) \\
-\mathrm{F} 508 \mathrm{del} / 1066 \mathrm{C} \\
(\mathrm{n}=1) \\
-\mathrm{F} 508 \mathrm{del} / \mathrm{I} 507 \\
(\mathrm{n}=1)\end{array}$ \\
\hline Age & 12 years & 24 years & 25 years & $\begin{array}{l}7 \text { patients: Range } \\
17-39 \text { years }\end{array}$ \\
\hline Presentation & $\begin{array}{l}\text {-Rash -Serum } \\
\text { sickness like } \\
\text { reaction -Fever, } \\
\text { nausea, vomiting } \\
\text {-Abdominal pain, } \\
\text { pruritic } \\
\text { erythematous rash, } \\
\text { targetoid lesions } \\
\text {-Lip swelling, joint } \\
\text { pain, tachycardia, } \\
\text { hypotension } \\
\text {-Increased } \\
\text { inflammatory } \\
\text { markers }\end{array}$ & $\begin{array}{l}\text {-Rash -Widespread, } \\
\text { urticarial -Back, } \\
\text { thighs and right } \\
\text { arm -No systemic } \\
\text { symptoms described }\end{array}$ & $\begin{array}{l}\text {-History of prior } \\
\text { catamenial } \\
\text { hemoptysis } \\
\text { controlled with } \\
\text { OCPs -Catamenial } \\
\text { hemoptysis }\end{array}$ & $\begin{array}{l}\text {-Testicular pain } \\
\text {-One reported urine } \\
\text { more concentrated } \\
\& \text { - ejaculate } \\
\text { volume -One } \\
\text { reported lower } \\
\text { abdominal pain and } \\
\text { difficulty urinating } \\
\text {-Several had work } \\
\text { up: UA/BMP, } \\
\text { Ultrasound (ab- } \\
\text { domen/testicular), } \\
\text { abdominal CT scan }\end{array}$ \\
\hline $\begin{array}{l}\text { Onset (timing after } \\
\text { starting modulator) }\end{array}$ & 5 days & 8 days & $\begin{array}{l}\text {-Within } 1 \text { year, not } \\
\text { described }\end{array}$ & $\begin{array}{l}\text {-Within } 2 \text { weeks - } 6 \\
\text { out of } 7 \text { occurred } \\
\text { within } 7 \text { days }\end{array}$ \\
\hline
\end{tabular}




\begin{tabular}{|c|c|c|c|c|}
\hline & $\operatorname{Rash}^{46}$ & $\operatorname{Rash}^{47}$ & Hemoptysis ${ }^{48}$ & $\begin{array}{l}\text { Testicular pain } \\
49\end{array}$ \\
\hline Treatment & $\begin{array}{l}\text {-ETI withdrawal } \\
\text {-Oral corticosteroids } \\
\text { Supportive care }\end{array}$ & $\begin{array}{l}\text {-Oral antihistamines } \\
\text {-Oral corticosteroids }\end{array}$ & $\begin{array}{l}\text {-Transitioned off } \\
\text { OCPs } \\
\text {-Levonorgesterol } \\
\text { IUD placed } \\
\text {-Hemoptysis } \\
\text { continued } \\
\text {-Bronchoscopy } \\
\text { showed tracheal } \\
\text { hyperemia -Biopsy } \\
\text { did not show } \\
\text { endometrial tissue } \\
\text {-Lesions felt to be } \\
\text { thoracic } \\
\text { endometriosis } \\
\text {-Reproductive } \\
\text { endocrinology } \\
\text { treated her with } 6 \\
\text { months } \\
\text { leuprolide(synthetic } \\
\text { gonadotropin } \\
\text { releasing agent) }\end{array}$ & $\begin{array}{l}\text {-Discontinuation of } \\
\text { ETI in } 1 \text {-Over the } \\
\text { counter pain } \\
\text { medications in } 3 \\
\text {-Antibiotics in } 1 \\
\text { (US had shown } \\
\text { swelling of the } \\
\text { scrotum) }\end{array}$ \\
\hline Outcome & $\begin{array}{l}\text {-Improvement } \\
\text { within } 24 \text { hours } \\
\text {-Complete } \\
\text { resolution within } 3 \\
\text { weeks }\end{array}$ & $\begin{array}{l}\text {-Rash subsided } \\
\text { within } 1 \text { week }\end{array}$ & $\begin{array}{l}\text {-Switched to tez/iva } \\
\text {-Switched to OCPs } \\
\text {-No further } \\
\text { hemoptysis -2019- } \\
\text { switched to ETI } \\
\text { once approved }\end{array}$ & $\begin{array}{l}\text {-All cases resolved } \\
\text { within } 3 \text { weeks, } \\
\text { regardless of } \\
\text { management } \\
\text { methods }\end{array}$ \\
\hline $\begin{array}{l}\text { Observation or } \\
\text { Conclusion }\end{array}$ & $\begin{array}{l}\text {-Long term } \\
\text { information about } \\
\text { potential } \\
\text { re-initiation of ETI } \\
\text { was not included }\end{array}$ & $\begin{array}{l}\text {-Safe re-initiation of } \\
\text { ETI was possible } \\
\text { several weeks later } \\
\text { with cautious } \\
\text { titration of the } \\
\text { dosing }\end{array}$ & $\begin{array}{l}\text {-It was felt that } \\
\text { lum/iva may have } \\
\text { - efficacy of OCPs, } \\
\text { - susceptibility to } \\
\text { catamenial } \\
\text { hemoptysis due to } \\
\text { thoracic } \\
\text { endometriosis }\end{array}$ & $\begin{array}{l}\text {-Only one held ETI } \\
\text { due to the testicular } \\
\text { pain; -ETI was able } \\
\text { to be slowly } \\
\text { introduced without } \\
\text { recurrence of pain }\end{array}$ \\
\hline
\end{tabular}

Abbreviations: lum/iva: lumacaftor/ivacaftor; ETI: elexecaftor/tezacaftor/ivacaftor; tez/iva: tezacaftor/ivacaftor; UA: urinalysis, BMP: basic metabolic panel; OCPs: oral contraceptives.

References

1. Incorporated VP. FDA Approves KALYDECOß (ivacaftor) as First and Only CFTR Modulator to Treat Eligible Infants With CF as Early as Four Months of Age2020 September 25, 2020.

2. Incorporated VP. Vertex Announces FDA Approvals of TRIKAFTA@ (elexacaftor/tezacaftor/ivacaftor and ivacaftor), SYMDEKOß, (tezacaftor/ivacaftor and ivacaftor) and KALYDECOß (ivacaftor) for Use in People With CF With Certain Rare Mutations. 2020.

3. Davies JC, Wainwright CE, Sawicki GS, Higgins MN, Campbell D, Harris C, Panorchan P, Haseltine E, Tian S, Rosenfeld M, Group AS. Ivacaftor in Infants Aged 4 to $<12$ Months With Cystic Fibrosis and a 
Gating Mutation: Results of a 2-Part Phase 3 Clinical Trial. Am J Respir Crit Care Med 2020.

4. Pilewski JM, De Boeck K, Nick JA, Tian S, DeSouza C, Higgins M, Moss RB. Long-Term Ivacaftor in People Aged 6 Years and Older with Cystic Fibrosis with Ivacaftor-Responsive Mutations. Pulm Ther 2020;6(2):303-313.

5. Higgins M, Volkova N, Moy K, Marshall BC, Bilton D. Real-World Outcomes Among Patients with Cystic Fibrosis Treated with Ivacaftor: 2012-2016 Experience. Pulm Ther 2020;6(1):141-149.

6. Volkova N, Moy K, Evans J, Campbell D, Tian S, Simard C, Higgins M, Konstan MW, Sawicki GS, Elbert A, Charman SC, Marshall BC, Bilton D. Disease progression in patients with cystic fibrosis treated with ivacaftor: Data from national US and UK registries. J Cyst Fibros 2019.

7. Bessonova L, Volkova N, Higgins M, Bengtsson L, Tian S, Simard C, Konstan MW, Sawicki GS, Sewall A, Nyangoma S, Elbert A, Marshall BC, Bilton D. Data from the US and UK cystic fibrosis registries support disease modification by CFTR modulation with ivacaftor. Thorax 2018;73(8):731-740.

8. Griese M, Costa S, Linnemann RW, Mall MA, McKone EF, Polineni D, Quon BS, Ringshausen FC, TaylorCousar JL, Withers NJ, Moskowitz SM, Daines CL. Safety and Efficacy of Elexacaftor/Tezacaftor/Ivacaftor for $>/=24$ Weeks in People With CF and $>/=1$ F508del Allele: Interim Results of an Open-Label Phase Three Clinical Trial. Am J Respir Crit Care Med 2020.

9. Keating D, Marigowda G, Burr L, Daines C, Mall MA, McKone EF, Ramsey BW, Rowe SM, Sass LA, Tullis E, McKee CM, Moskowitz SM, Robertson S, Savage J, Simard C, Van Goor F, Waltz D, Xuan F, Young T, Taylor-Cousar JL, Group VXS. VX-445-Tezacaftor-Ivacaftor in Patients with Cystic Fibrosis and One or Two Phe508del Alleles. N Engl J Med 2018;379(17):1612-1620.

10. Middleton P, Mall MA, Drevinek P, Lands LC, McKone EF, Polineni D. Elexacaftor-Tezacaftor-Ivacaftor for Cystic Fibrosis with a Single Phe508del Allele. NEJM 2019;381:1809-1819.

11. Ejiofor LCK, Mathiesen IHM, Jensen-Fangel S, Olesen HV, Skov M, Philipsen LKD, Pedersen CL, Pressler T. Patients with cystic fibrosis and advanced lung disease benefit from lumacaftor/ivacaftor treatment. Pediatr Pulmonol 2020;55(12):3364-3370.

12. Tong K, Barker D, France M, Burr L, Greville H, Visser S, Middleton P, Wainwright C, Dorahy D, Wark P. Lumacaftor/ivacaftor reduces exacerbations in adults homozygous for Phe508del mutation with severe lung disease. J Cyst Fibros 2020;19(3):415-420.

13. O'Shea KM, O'Carroll OM, Carroll C, Grogan B, Connolly A, O'Shaughnessy L, Nicholson T, Gallagher CG, McKone EF. The efficacy of Elexacaftor/Tezacaftor/Ivacaftor in patients with cystic fibrosis and advanced lung disease. Eur Respir J 2020.

14. Aalbers BL, de Winter-de Groot KM, Arets HGM, Hofland RW, de Kiviet AC, van Oirschot-van de Ven MMM, Kruijswijk MA, Schotman S, Michel S, van der Ent CK, Heijerman HGM. Clinical effect of lumacaftor/ivacaftor in F508del homozygous CF patients with FEV1 $>/=90 \%$ predicted at baseline. J Cyst Fibros 2020;19(4):654-658.

15. Davies JC, Sermet-Gaudelus I, Naehrlich L, Harris RS, Campbell D, Ahluwalia N, Short C, Haseltine E, Panorchan P, Saunders C, Owen CA, Wainwright CE, Group VXI. A phase 3, double-blind, parallel-group study to evaluate the efficacy and safety of tezacaftor in combination with ivacaftor in participants 6 through 11 years of age with cystic fibrosis homozygous for F508del or heterozygous for the F508del-CFTR mutation and a residual function mutation. J Cyst Fibros 2020.

16. Shaw M, Khan U, Clancy JP, Donaldson SH, Sagel SD, Rowe SM, Ratjen F, Network PIotCFFTD. Changes in LCI in F508del/F508del patients treated with lumacaftor/ivacaftor: Results from the prospect study. J Cyst Fibros 2020;19(6):931-933. 
17. Ratjen F, Davis SD, Stanojevic S, Kronmal RA, Hinckley Stukovsky KD, Jorgensen N, Rosenfeld M, Group SS. Inhaled hypertonic saline in preschool children with cystic fibrosis (SHIP): a multicentre, randomised, double-blind, placebo-controlled trial. Lancet Respir Med 2019;7(9):802-809.

18. Kerem E, Cohen-Cymberknoh M, Tsabari R, Wilschanski M, Reiter J, Shoseyov D, Gileles-Hillel A, Pugatsch T, Davies JC, Short C, Saunders C, DeSouza C, Sullivan JC, Doyle JR, Chandarana K, Kinnman N. Ivacaftor in People With Cystic Fibrosis and a $3849+10 \mathrm{~kb}$ C $->$ T or D1152H Residual Function Mutation. Ann Am Thorac Soc 2020.

19. Nick JA, St Clair C, Jones MC, Lan L, Higgins M, Team VXS. Ivacaftor in cystic fibrosis with residual function: Lung function results from an N-of-1 study. J Cyst Fibros 2020;19(1):91-98.

20. Berkers G, van der Meer R, Heijerman H, Beekman JM, Boj SF, Vries RGJ, van Mourik P, Doyle JR, Audhya P, Yuan ZJ, Kinnman N, van der Ent CK. Lumacaftor/ivacaftor in people with cystic fibrosis with an A455E-CFTR mutation. J Cyst Fibros 2020.

21. Beekman JM. Individualized medicine using intestinal responses to CFTR potentiators and correctors. Pediatr Pulmonol 2016;51:S23-S34.

22. Burghard MM, Berkers GG, Ghijsen SS, Hollander-Kraaijeveld FF, de Winter-de Groot KK, van der Ent CK, Heijerman HH, Takken TT, Hulzebos HE. Long-term effects of ivacaftor on nonpulmonary outcomes in individuals with cystic fibrosis, heterozygous for a S1251N mutation. Pediatr Pulmonol 2020;55(6):1400-1405.

23. Quon BS, Ramsook AH, Dhillon SS, Mitchell RA, Boyle KG, Wilcox PG, Guenette JA. Short-term effects of Lumacaftor/Ivacaftor (Orkambi) on exertional symptoms, exercise performance, and ventilatory responses in adults with cystic fibrosis. Respir Res 2020;21(1):135.

24. Lundberg JO NS, Weitzberg E, Kollberg H, Alving K. Exhaled NO in paediatric asthma and cystic fibrosis. Arch Dis Child 1996;75(4):323-326.

25. Thomas SR KS, Scott SF, Hodson ME, Barnes PJ. Nasal and exhaled nitric oxide is reduced in adult patients with cystic fibrosis and does not correlate with cystic fibrosis genotype. Chest 2000;117:1085-1089.

26. Gostelie R, Stegeman I, Berkers G, Bittermann J, Ligtenberg-van der Drift I, Kipshagen PV, de Winterde Groot K, Speleman L. The impact of ivacaftor on sinonasal pathology in S1251N-mediated cystic fibrosis patients. PLoS One 2020;15(7):e0235638.

27. Walker WT LA, Harris A, Cole J, Lucas JS. Upper and lower airway nitric oxide levels in primary ciliary dyskinesia, cystic fibrois and asthma. Respiratory Medicine 2013;107:380-386.

28. Rachel M BM, Aebisher D, Galiniak S. Exhaled nitric oxide in pediatric patients with respiratory disease. J Breath Res 2019;18:13.

29. Grasemann H, Klingel M, Avolio J, Prentice C, Gonska T, Tullis E, Ratjen F. Long-term effect of CFTR modulator therapy on airway nitric oxide. Eur Respir J 2020;55(1).

30. Grasemann H. GT, Avolio J. Effect of iva therapy on exhaled nitric oxide in patients with cystic fibrosis. J Cyst Fibros 2015;14:727-732.

31. Kotha K SR, Naren AP et al. Concentration of fractional excretion of nitric oxide (FeNO): a potential airway biomarker of restored CFTR function. J Cyst Fibros 2015;14:733-740.

32. Munck A, Kerem E, Ellemunter H, Campbell D, Wang LT, Ahluwalia N, Owen CA, Wainwright C. Tezacaftor/ivacaftor in people with cystic fibrosis heterozygous for minimal function CFTR mutations. J Cyst Fibros 2020;19(6):962-968.

33. McKone EF, DiMango EA, Sutharsan S, Barto TL, Campbell D, Ahluwalia N, Higgins M, Owen CA, Tullis E. A phase 3, randomized, double-blind, parallel-group study to evaluate tezacaftor/ivacaftor in people with cystic fibrosis heterozygous for F508del-CFTR and a gating mutation. J Cyst Fibros 2020. 
34. Munce D, Lim M, Akong K. Persistent recovery of pancreatic function in patients with cystic fibrosis after ivacaftor. Pediatr Pulmonol 2020;55(12):3381-3383.

35. Hutchinson I MP. Appearance of Pancreatic Sufficiency and Discontinuation of Pancreatic Enzyme Replacement Therapy in Children with Cystic Fibrosis on Ivacaftor. Ann Am Thorac Soc 2021;18:182-183.

36. Wright BA, Cannon ME, Ramsey LJ. Reversing the irreversible: Another potential benefit of CFTR modulators. Pediatr Pulmonol 2020;55(11):2844-2845.

37. Smith H, Rayment JH. Sustained recovery of exocrine pancreatic function in a teenager with cystic fibrosis treated with ivacaftor. Pediatr Pulmonol 2020.

38. Moheet A, Beisang D, Zhang L, Sagel SD, VanDalfsen JM, Heltshe SL, Frederick C, Mann M, Antos N, Billings J, Rowe SM, Moran A, Network PIotCFFTD. Lumacaftor/ivacaftor therapy fails to increase insulin secretion in F508del/F508del CF patients. J Cyst Fibros 2020.

39. Misgault B, Chatron E, Reynaud Q, Touzet S, Abely M, Melly L, Dominique S, Troussier F, RonsinPradel O, Gerardin M, Mankikian J, Cosson L, Chiron R, Bounyar L, Porzio M, Durieu I, Weiss L, Kessler R, Kessler L. Effect of one-year lumacaftor-ivacaftor treatment on glucose tolerance abnormalities in cystic fibrosis patients. J Cyst Fibros 2020;19(5):712-716.

40. Moran A, Brunzell C, Cohen R, Katz M, Marshall b, Onady G et al. Clinical care guidelines for CF related diabetes mellitus. Diabetes Care 2010;33:2697-2708.

41. Secunda KE, Guimbellot JS, Jovanovic B, Heltshe SL, Sagel SD, Rowe SM, Jain M. Females with Cystic Fibrosis Demonstrate a Differential Response Profile to Ivacaftor Compared with Males. Am J Respir Crit Care Med 2020;201(8):996-998.

42. Ladores S, Bray LA, Brown J. Two Unanticipated Pregnancies While on Cystic Fibrosis Gene-Specific Drug Therapy. J Patient Exp 2020;7(1):4-7.

43. O'Connor KE, Goodwin DL, NeSmith A, Garcia B, Mingora C, Ladores SL, Rowe SM, Krick S, Solomon GM. Elexacafator/tezacaftor/ivacaftor resolves subfertility in females with CF: A two center case series. J Cyst Fibros 2020.

44. Nash EF, Middleton PG, Taylor-Cousar JL. Outcomes of pregnancy in women with cystic fibrosis (CF) taking CFTR modulators - an international survey. J Cyst Fibros 2020;19(4):521-526.

45. Taylor-Cousar JL. CFTR modulators: impact on fertility, pregnancy and lactation in women with cystic fibrosis. J Clin Med 2020;9:2706.

46. Brennan S, Marmor I, Schafer C, Ko J, Torres Garcia JA, Rosman IS, Coughlin C, Coverstone A, White AJ. Serum sickness-like reaction following initiation of elexacaftor/tezacaftor/ivacaftor therapy. Pediatr Pulmonol 2020.

47. Hu MK, Wood G, Dempsey O. 'Triple therapy' (elexacaftor, tezacaftor, ivacaftor) skin rash in patients with cystic fibrosis. Postgrad Med J 2020.

48. Montemayor K, Claudio AT, Carson S, Lechtzin N, Christianson MS, West NE. Unmasking catamenial hemoptysis in the era of CFTR modulator therapy. J Cyst Fibros 2020;19(4):e25-e27.

49. Rotolo SM, Duehlmeyer S, Slack SM, Jacobs HR, Heckman B. Testicular pain following initiation of elexacaftor/tezacaftor/ivacaftor in males with cystic fibrosis. J Cyst Fibros 2020;19(5):e39-e41.

50. Albright JC, Houck AP, Pettit RS. Effects of CFTR modulators on pharmacokinetics of tobramycin during acute pulmonary exacerbations in the pediatric cystic fibrosis population. Pediatr Pulmonol 2020.

51. Baker E, Harris WT, Rowe SM, Rutland SB, Oates GR. Tobacco smoke exposure limits the therapeutic benefit of tezacaftor/ivacaftor in pediatric patients with cystic fibrosis. J Cyst Fibros 2020. 
52. Loukou I, Moustaki M, Plyta M, Douros K. Longitudinal changes in lung function following initiation of lumacaftor/ivacaftor combination. J Cyst Fibros 2020;19(4):534-539.

53. Burgel PR, Munck A, Durieu I, Chiron R, Mely L, Prevotat A, Murris-Espin M, Porzio M, Abely M, Reix P, Marguet C, Macey J, Sermet-Gaudelus I, Corvol H, Bui S, Lemonnier L, Dehillotte C, Da Silva J, Paillasseur JL, Hubert D, French Cystic Fibrosis Reference Network Study G. Real-Life Safety and Effectiveness of Lumacaftor-Ivacaftor in Patients with Cystic Fibrosis. Am J Respir Crit Care Med 2020;201(2):188-197.

54. Salvatore D, Carnovale V, Majo F, Padoan R, Salvatore M, Taruscio D, Amato A, Ferrari G, Campagna G. Cystic fibrosis with non-G551D gating mutations in Italy: Epidemiology and clinical characteristics. Pediatr Pulmonol 2020.

55. Sala MA, Jain M. Combination Therapy with Lumacaftor-Ivacaftor in Cystic Fibrosis. Keeping It Real. Am J Respir Crit Care Med 2020;201(2):133-134.

56. Tong K BD, France M, Burr L, Greville H, Visser S, MIddleton P, Wainwright C, Dorahy D, Wark P. Lum/iva reduces exacerbations in adults homozygous for F508del mutation with severe lung disease. Journal of Cystic Fibrosis 2020;19:415-420.

57. Olivereau L, Nave V, Garcia S, Perceval M, Rabilloud M, Durieu I, Reynaud Q. Adherence to lumacaftorivacaftor therapy in patients with cystic fibrosis in France. J Cyst Fibros 2020;19(3):402-406.

58. Schwarz C, Sutharsan S, Epaud R, Klingsberg RC, Fischer R, Rowe SM, Audhya PK, Ahluwalia N, You X, Ferro TJ, Duncan ME, Bruinsma BG. Tezacaftor/ivacaftor in people with cystic fibrosis who stopped lumacaftor/ivacaftor due to respiratory adverse events. J Cyst Fibros 2020.

59. Smith A, Barry M. Utilisation, expenditure and cost-effectiveness of cystic fibrosis drugs in Ireland: a retrospective analysis of a national pharmacy claims database. BMJ Open 2020;10(11):e040806.

60. Wherry K, Williamson I, Chapman RH, Kuntz KM. Cost-Effectiveness of Ivacaftor Therapy for Treatment of Cystic Fibrosis Patients With the G551D Gating Mutation. Value Health 2020;23(10):1332-1339.

61. Cobanoglu N, Ozcelik U, Cakir E, Sismanlar Eyuboglu T, Pekcan S, Cinel G, Yalcin E, Kiper N, Emiralioglu N, Sen V, Sen HS, Ercan O, Cokugras H, Kilinc AA, Al Shadfan LM, Yazan H, Altintas DU, Karagoz D, Demir E, Kartal Ozturk G, Bingol A, Basaran AE, Sapan N, Cekic S, Celebioglu E, Aslan AT, Gursoy TR, Tugcu G, Ozdemir A, Harmanci K, Yildirim GK, Kose M, Hangul M, Tamay Z, Suleyman A, Yuksel H, Yilmaz O, Ozcan G, Topal E, Can D, Korkmaz Ekren P, Caltepe G, Kilic M, Ozdogan S, Dogru D. Patients eligible for modulator drugs: Data from cystic fibrosis registry of Turkey. Pediatr Pulmonol 2020.

62. Desai S, Lam GY, Sykes J, Stephenson AL, Quon BS. Eligibility of CFTR modulators for the adultdiagnosed cystic fibrosis population. J Cyst Fibros 2020;19(5):840-841.

63. McGarry M. Transparency and diversity in cystic fibrosis research. Lancet 2020;396(10251):601.

64. McGarry ME. Triple Therapy for Cystic Fibrosis with a Phe508del CFTR Mutation. N Engl J Med 2020;382(7):684.

65. De Boeck K, Lee T, Amaral M, Drevinek P, Elborn JS, Fajac I, Kerem E, Davies JC. Cystic fibrosis drug trial design in the era of CFTR modulators associated with substantial clinical benefit: stakeholders' consensus view. J Cyst Fibros 2020;19(5):688-695.

66. Mayer-Hamblett N, van Koningsbruggen-Rietschel S, Nichols DP, VanDevanter DR, Davies JC, Lee T, Durmowicz AG, Ratjen F, Konstan MW, Pearson K, Bell SC, Clancy JP, Taylor-Cousar JL, De Boeck K, Donaldson SH, Downey DG, Flume PA, Drevinek P, Goss CH, Fajac I, Magaret AS, Quon BS, Singleton SM, VanDalfsen JM, Retsch-Bogart GZ. Building global development strategies for cf therapeutics during a transitional cftr modulator era. J Cyst Fibros 2020;19(5):677-687. 
67. Magaret A, Warden M, Simon N, Heltshe S, Mayer-Hamblett N. Real-world evidence in cystic fibrosis modulator development: Establishing a path forward. J Cyst Fibros 2020;19(3):e11-e12.

68. Mall MA, Mayer-Hamblett N, Rowe SM. Cystic Fibrosis: Emergence of Highly Effective Targeted Therapeutics and Potential Clinical Implications. Am J Respir Crit Care Med 2020;201(10):1193-1208.

69. George A, Smith B, Sawicki GS, Goetz DM. Survey of patients with cystic fibrosis and caregivers decisions regarding CFTR modulators. Pediatr Pulmonol 2020.

70. Gifford AH, Mayer-Hamblett N, Pearson K, Nichols DP. Answering the call to address cystic fibrosis treatment burden in the era of highly effective CFTR modulator therapy. J Cyst Fibros 2020;19(5):762-767.

71. NCT04378153 CgI. Impact of Discontinuing Chronic Therapies in People With Cystic Fibrosis on Highly Effective CFTR Modulator Therapy (SIMPLIFY).

72. Konstan MW, VanDevanter DR, Rowe SM, Wilschanski M, Kerem E, Sermet-Gaudelus I, DiMango E, Melotti P, McIntosh J, De Boeck K, Group ACS. Efficacy and safety of ataluren in patients with nonsense-mutation cystic fibrosis not receiving chronic inhaled aminoglycosides: The international, randomized, double-blind, placebo-controlled Ataluren Confirmatory Trial in Cystic Fibrosis (ACT CF). J Cyst Fibros 2020;19(4):595-601.

73. Peabody Lever JE, Mutyam V, Hathorne HY, Peng N, Sharma J, Edwards LJ, Rowe SM. Ataluren/ivacaftor combination therapy: Two N-of-1 trials in cystic fibrosis patients with nonsense mutations. Pediatr Pulmonol 2020;55(7):1838-1842.

74. van Koningsbruggen-Rietschel S, Conrath K, Fischer R, Sutharsan S, Kempa A, Gleiber W, Schwarz C, Hector A, Van Osselaer N, Pano A, Corveleyn S, Bwirire D, Santermans E, Muller K, Bellaire S, Van de Steen O. GLPG2737 in lumacaftor/ivacaftor-treated CF subjects homozygous for the F508del mutation: A randomized phase 2A trial (PELICAN). J Cyst Fibros 2020;19(2):292-298.

75. Kazani S, Rowlands DJ, Bottoli I, Milojevic J, Alcantara J, Jones I, Kulmatycki K, Machineni S, Mostovy L, Nicholls I, Nick JA, Rowe SM, Simmonds NJ, Vegesna R, Verheijen J, Danahay H, Gosling M, Ayalavajjala PS, Salman M, Strieter R. Safety and efficacy of the cystic fibrosis transmembrane conductance regulator potentiator icenticaftor (QBW251). J Cyst Fibros 2020.

76. Drevinek P, Pressler T, Cipolli M, De Boeck K, Schwarz C, Bouisset F, Boff M, Henig N, PaquetteLamontagne N, Montgomery S, Perquin J, Tomkinson N, den Hollander W, Elborn JS. Antisense oligonucleotide eluforsen is safe and improves respiratory symptoms in F508DEL cystic fibrosis. J Cyst Fibros 2020;19(1):99-107. 